\title{
(6) OPEN ACCESS \\ Community paramedics treat high acuity conditions in the home: a prospective observational study
}

\section{Karen Anna Abrashkin, ${ }^{\oplus 1}$ Asantewaa Poku, ${ }^{1}$ Alyeah Ramjit, ${ }^{2}$ Jonathan Washko, ${ }^{2}$ Jenny Zhang, ${ }^{3}$ Michael Guttenberg, ${ }^{2}$ Kristofer Lawrence Smith ${ }^{1}$}

\begin{abstract}
${ }^{1}$ Health Solutions, Northwell Health, New Hyde Park, New York, USA

${ }^{2}$ Center for Emergency Medical Services, Northwell Health, Syosset, New York, USA ${ }^{3}$ Donald and Barbara Zucker School of Medicine at Hofstra/ Northwell, Hempstead, New York, USA
\end{abstract}

\section{Correspondence to}

Dr Karen Anna Abrashkin, Health Solutions, Northwell Health, New Hyde Park, NY 11042, USA; kabrashkin@northwell.edu

Received 18 December 2018 Revised 8 March 2019 Accepted 20 March 2019

\section{Check for updates}

(c) Author(s) (or their employer(s)) 2019. Re-use permitted under CC BY-NC. No commercial re-use. See rights and permissions. Published by BMJ.

To cite: Abrashkin KA, Poku A, Ramjit A, et al. BMJ Supportive \& Palliative Care Epub ahead of print: [please include Day Month Year]. doi:10.1136/ bmjspcare-2018-001746

\section{ABSTRACT}

Objectives As the US population ages and healthcare reimbursement shifts, identifying new patient-centred, cost-effective models to address acute medical needs will become increasingly important. This study examined whether community paramedics can evaluate and treat, under the direction of a credentialed physician, high acuity medical conditions in the home within an advanced illness management (AIM) practice.

Methods A prospective observational study of an urban/suburban community paramedicine (CP) programme, with responses initiated based on AIM-practice protocols and triaged prior to dispatch using the Advanced Medical Priority Dispatch System (AMPDS). Primary outcome was association between AMPDS acuity levels and emergency department (ED) transport rates. Secondary outcomes were ED presentations at 24 and 48 hours post-visit, and patient/caregiver survey results.

Results 1159 individuals received 2378 CP responses over 4 years. Average age was 86 years; dementia, heart failure and asthma/ chronic obstructive pulmonary disease were prevalent. Using AMPDS, most common reasons for dispatch included 'breathing problems' (28.2\%), 'sick person' (26.5\%) and 'falls' (13.1\%). High acuity responses were most prevalent. $17.9 \%$ of all responses and $21.0 \%$ of high acuity responses resulted in ED transport. Within 48 hours of the visit, only $5.7 \%$ of the high acuity responses not initially transported were transported to the ED. Patient/caregiver satisfaction rates were high.

Conclusion Community paramedics, operating within an AIM programme, can evaluate and treat a range of conditions, including high acuity conditions, in the home that would typically result in ED transport in a conventional 911 system. This model may provide an effective means for avoiding hospital-based care, allowing older adults to age in place.

\section{INTRODUCTION}

As the US population ages, developing patient-centred and cost-effective delivery models for treatment of acute unscheduled medical events will become increasingly important. Current models of care often fail to provide older individuals meaningful clinical responses in a timely manner, leading to unwanted or unneeded hospital utilisation and the often-associated decline in cognitive and functional status. ${ }^{1-3}$ These dynamics explain part of the high cost of medical care in the USA and its concentration in the final 3 years of life. ${ }^{4}$

Physician extender models using paramedics with additional training, a concept known as community paramedicine (CP) or mobile integrated healthcare, are currently used in a diverse array of settings throughout the USA. In rural communities, these paramedics are serving in a primary care role, while in other settings they are targeting specific populations with more acute care needs. ${ }^{5-10}$ The optimal role for paramedics as physician extenders has yet to be defined but the concept shows promise. Indeed, the Center for Medicare and Medicaid Services (CMS) recently announced plans to offer an alternative payment model that would allow Emergency Medical Services (EMS), which operate under medical control, the flexibility to treat patients in their homes or transport to an alternative destination other than the emergency department (ED). ${ }^{11}$ The potential for community paramedics to safely and effectively intervene on acute clinical decompensations in a frail population of older adults as part of a multidisciplinary team has not been fully evaluated to date. The paramedic operating model may fit the needs of an ageing population well: paramedics 
are available around-the-clock, are comfortable with high acuity medical conditions, carry medications and diagnostics, and are accustomed to working under the guidance of a physician in a team-based approach.

Using paramedics to evaluate and treat patients in the home setting could have wide-reaching implications for population health management, patient satisfaction, patient safety and cost of care in many populations, including homebound older adults. The overall goal of this investigation was, therefore, to explore whether high acuity conditions that would typically result in transport to the ED in a conventional 911 system can be effectively treated at home using a physician extender CP model within an advanced illness management (AIM) programme.

\section{METHODS}

\section{Study design and setting}

This was a prospective observational study of outcomes from a CP programme operating in Queens, Nassau and Suffolk counties, New York. The programme operates within an integrated delivery system that includes an EMS agency which provides primary 911 services and air and ground transport, as well as an AIM programme serving homebound individuals with multiple chronic medical conditions.

Our AIM programme consists of nine primary care providers (physicians and nurse practitioners), five social workers, five registered nurses and seven medical coordinators who annually provide home-based primary care to approximately 2000 homebound individuals. The programme serves the primary care needs of this population, in addition to meeting acute and unscheduled needs with same and next-day visits when indicated, and around-the-clock telephonic access to a call centre staffed by registered nurses who can escalate to the programme's primary care providers when needed.

The organisation's EMS agency includes approximately 600 emergency responders (emergency medical technicians and paramedics). A subset of these front-line staff are community paramedics: critical care paramedics who have received additional instruction in geriatrics, home-based primary care and palliative care. These paramedics are trained to provide urgent and emergent care for those enrolled in the AIM programme, but are not solely dedicated to this programme and may be dispatched for multiple call types outside of the $\mathrm{CP}$ programme during any given time period. Community paramedics carry an on-board formulary of medications (intravenous, oral, nebulised) as well as diagnostics (12-lead EKGs, capnography, blood glucose monitoring).

$\mathrm{CP}$ responses are initiated based on clinical protocols and at the discretion of AIM clinicians. When an AIM enrollee calls the programme with a change in condition, one of four options exist depending on clinical need: telephonic advice from an AIM nurse or

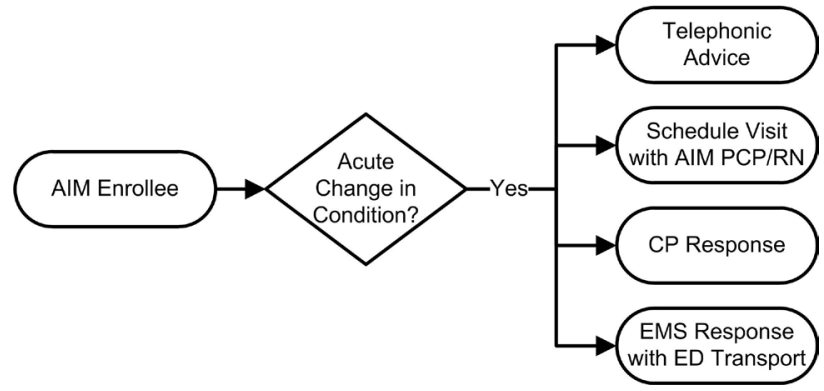

Figure 1 Options for responding to change in clinical condition in the aim programme depending on clinical need. AIM, Advanced Ilness Management; PCP, Primary Care Provider (physician or nurse practitioner); $R N$, registered nurse; $C P$, community paramedicine; EMS, Emergency Medical Services; $E D$, emergency department

provider, schedule a visit with an AIM clinician, CP response or EMS response for expected ED transport (figure 1). Following the decision to dispatch $\mathrm{CP}$, an AIM clinician contacts our system's emergency medical dispatchers (EMDs) who route the closest team to the patient home. Calls are triaged using the Advanced Medical Priority Dispatch System (AMPDS, V.13.1.171; Priority Dispatch Corporation, Salt Lake City, Utah, USA) within our EMS agency prior to dispatch. AMPDS provides a system to dispatch appropriate EMS resources to medical emergencies (basic life support vs advanced cardiac life support, no lights and sirens vs lights and sirens). The system is used internationally and includes 32 numbered 'cards' allowing each call to be categorised into a discrete clinical complaint. Systematic questioning generates a call acuity level, from low acuity (OMEGA and ALPHA) to moderate (BRAVO) to high (CHARLIE and DELTA) and cardiac or respiratory arrest (ECHO). In this system, higher acuity complaints result in higher level emergency responses (ie, faster response times with more extensive capabilities).

Evaluation and treatment of each CP response is overseen by AIM physicians (internists, family medicine practitioners, geriatricians and palliative caretrained physicians) who are credentialed to provide New York State Online Medical Control (OLMC). Video conferencing between paramedic and OLMC is used when available. Details of community paramedic training and operations have been previously published. ${ }^{6}$

\section{Selection of participants}

All individuals enrolled in the AIM programme were eligible to receive care through the CP programme. Enrolment criteria for the AIM programme include being home-bound with two or more chronic conditions. Most enrollees are over age 65 years (average enrollee age during the study period was 84 years), have acute care use (hospital and ED use) in the year prior to enrolment and have multiple activities of 
daily living dependencies. Community paramedics were dispatched at the discretion of the AIM provider for situations in which in-home evaluation and treatment was both desired based on patient goals of care, and deemed appropriate considering diagnostic and formulary capabilities of the community paramedics. This research was approved by our institution's Institutional Review Board.

\section{Interventions}

Interventions included community paramedic responses as well as confidential patient/caregiver surveys. Community paramedic responses included telephonic triage in which the AMPDS code was generated, evaluation by the community paramedic in the home, and video or telephonic conference with the OLMC physician with discussion of ED transport or attempted in home interventions as indicated. If the decision was made not to transport to the ED following in-home evaluation and/or treatment, follow-up was provided telephonically by registered nurses within 6 hours of the response. Follow-up care was also provided telephonically or in person by AIM programme staff as needed.

\section{Measurements}

We collected data on the AMPDS codes generated through systematic questioning by EMDs at the time of CP deployment, including 'card' (clinical complaint), and acuity level for each response. Acuity levels include (from low to high) OMEGA (nurse advice), ALPHA, BRAVO, CHARLIE, DELTA and ECHO (cardiopulmonary arrest). These data were extracted from the ProQA Paramount for Medical system (V.5.1.1.28; Priority Dispatch Corporation). On scene, community paramedics further documented clinical data as well as interventions performed during the response. These data were collected through HealthEMS (Sansio, Redmond, Washington, USA). We tracked the rates of patient transport to the ED within 24 and 48 hours of a CP response using data from our institutional health information exchange, the Regional Health Information Organization and internal data maintained by the AIM programme.

There were a number of responses for AMPDS 'sick person' and 'unknown problem' cards which required further investigation to understand the reason for the $\mathrm{CP}$ response. To this end, data extraction for examination and classification of all 'sick person' $(n=630)$ and 'unknown problem' $(\mathrm{n}=10)$ responses was done using HealthEMS. When adequate documentation could not be located in HealthEMS $(n=132)$, data were extracted from physician notes in the AIM electronic health record (EHR; Allscripts TouchWorks EHR V.15.1, Chicago, Illinois, USA). There were 12 'sick person' and 'unknown problem' records in which no clarifying documentation was found in HealthEMS or in the EHR.
Patient/caregiver satisfaction survey data regarding the $\mathrm{CP}$ response were obtained via paper mail surveys. Surveys were mailed within 1 week of the community paramedic visit; surveys were not mailed if the patient expired prior to the mailing. Survey questions included operational issues (timeliness of call answering, paramedic arrival), quality and satisfaction (quality of services provided, trust for the paramedic evaluation), and outcomes (respect for goals of care, likelihood to use in a future emergency and decrease in caregiver burden/stress). Patient/caregiver respondents were asked to reply using a 5 -option Likert scale. Additionally, the survey assessed what the patient/caregiver would have done had the CP programme not been available (dialled 911, gone to the emergency room, waited to see if the patient got better, other).

Baseline clinical and demographic data were extracted from the AIM EHR.

\section{Outcomes}

The primary outcome of this study was relationship between AMPDS acuity levels and rate of transport to an ED, with secondary outcomes including presentation to the ED within 24 and 48 hours of a CP response, and patient/caregiver satisfaction. Descriptive data, including reason for dispatch, response time, medications given and procedures performed, are also reported.

\section{Analysis}

Data were extracted from ProQA, HealthEMS and Allscripts and were stored in REDCap. Responses were analysed by acuity level as well as by card/chief complaint in REDCap. Patient/caregiver satisfaction survey results were transcribed into and tabulated in REDCap. Analysis of categorical variables was performed using $\chi^{2}$ tests in R (V.3.4.1).

\section{RESULTS}

\section{Characteristics of study subjects}

During the 4-year study period, 1 January 2014 to 31 December 2017, a total of 3137 unique patients were enrolled in the AIM programme. In total, 1159 individuals received $2378 \mathrm{CP}$ responses over the study period. For those individuals who received a $\mathrm{CP}$ response, average patient age was 86 years, $65 \%$ were women, $66 \%$ had primary Medicare insurance and $93 \%$ had completed advanced directives $(69 \%$ had a Do Not Resuscitate order and 39\% had a Do Not Hospitalise order). The population had high rates of dementia (50\%), pressure and chronic ulcers (42\%), heart failure (35\%), asthma or chronic obstructive pulmonary disease (28\%), diabetes (27\%) and cancer (10\%). Most individuals were dependent on assistance with five to six activities of daily living (ADLs) (72\%) (table 1). ADLs include walking, transferring, bathing, eating, toileting and dressing. ${ }^{12}$ 
Table 1 Patient characteristics of those receiving community paramedicine responses over the 4-year study period, $n=1159$

\begin{tabular}{|c|c|}
\hline Patient characteristics & Number $(\%)$ \\
\hline \multicolumn{2}{|l|}{ Sex } \\
\hline Male & $400(35)$ \\
\hline Female & $759(65)$ \\
\hline \multicolumn{2}{|l|}{ Age } \\
\hline$<70$ & $103(9)$ \\
\hline $70-79$ & $143(12)$ \\
\hline $80-89$ & $416(36)$ \\
\hline$>90$ & $497(43)$ \\
\hline \multicolumn{2}{|l|}{ No of activity of daily living dependencies } \\
\hline 0 & $90(8)$ \\
\hline $1-2$ & $91(8)$ \\
\hline $3-4$ & $116(10)$ \\
\hline $5-6$ & $829(72)$ \\
\hline \multicolumn{2}{|l|}{ Advance care planning } \\
\hline Advance care planning & $1076(93)$ \\
\hline Do Not Resuscitate order & $798(69)$ \\
\hline Do Not Hospitalise order & $457(39)$ \\
\hline \multicolumn{2}{|l|}{ Insurance status } \\
\hline Medicaid primary & $29(3)$ \\
\hline Medicare primary & $768(66)$ \\
\hline Private & $356(31)$ \\
\hline \multicolumn{2}{|l|}{ Chronic conditions } \\
\hline Hypertension & $819(71)$ \\
\hline $\begin{array}{l}\text { Alzheimer's disease and related disorders or } \\
\text { dementia }\end{array}$ & $580(50)$ \\
\hline Pressure and chronic ulcers & $488(42)$ \\
\hline Hyperlipidaemia & $501(43)$ \\
\hline Depression & $415(36)$ \\
\hline Heart failure & $405(35)$ \\
\hline $\begin{array}{l}\text { Asthma/chronic obstructive pulmonary disease } \\
\text { and bronchiectasis }\end{array}$ & $327(28)$ \\
\hline Rheumatoid arthritis/osteoarthritis & $397(34)$ \\
\hline Atrial fibrillation & $344(30)$ \\
\hline Diabetes & $309(27)$ \\
\hline Chronic kidney disease & $297(26)$ \\
\hline Stroke/transient ischaemic attack & $178(15)$ \\
\hline Cancer & $119(10)$ \\
\hline Osteoporosis & $102(9)$ \\
\hline
\end{tabular}

\section{Main results}

Average paramedic response time was $24.7 \mathrm{~min}$, and average time on scene was $73.4 \mathrm{~min}$. High acuity response levels (CHARLIE and DELTA level) were most common: $40.1 \%$ and $25.5 \%$, respectively. Other acuities were as follows: ALPHA (22.2\%), BRAVO (7.5\%), OMEGA (3.8\%) and ECHO (0.8\%) (figure 2). Responses were most commonly dispatched for 'breathing problems' (28.2\%), followed by 'sick person' $(26.5 \%)$ and 'falls' (13.1\%). High acuity responses (CHARLIE and DELTA level) were most commonly dispatched for 'breathing problems' (42.7\%), 'sick person' (20.3\%), 'unconscious/fainting' (12.7\%) and 'chest pain' (9.4\%). A subset of CP responses were also dispatched for the purpose of death pronouncement (3.9\%). Of note, given the small sample size of ECHO responses, mostly resulting in death pronouncements, $\mathrm{ECHO}$ responses were not included in the high acuity response calculations.

On analysis of the 'sick person' and 'unknown problem' visits $(n=640), 19.9 \%$ were further categorised as malaise/generalised weakness, $18.5 \%$ altered mental status, $8.5 \%$ dehydration, $6.9 \%$ breathing problem, $6.4 \%$ nausea/vomiting, $4.7 \%$ pain (non-chest pain) and $4.7 \%$ fever. Other complaints included dizziness, blood pressure problems, lift assist and syncope/ fainting. There were 23 responses $(3.6 \%)$ that could not be further classified.

Overall, $17.9 \%$ of community paramedic responses resulted in transport to the $\mathrm{ED}$, with transport rates varying by response level: OMEGA (1.1\%), ALPHA (11.5\%), BRAVO (20.7\%), CHARLIE (19.8\%), DELTA (21.7\%) and ECHO (0.0\%) (figure 2). Transport rate for those with completed advance directives was not statistically different from those without completed advance directives. Overall, excluding responses for death pronouncements, $89.6 \%$ of those who were transported and $91.4 \%$ of those who were not transported had completed advance directives $(p=0.21)$.

Of those individuals who were not transported or pronounced at the time of the CP response $(n=1820)$, $126(6.9 \%)$ were subsequently transported to an ED: $90(4.9 \%)$ were transported within 24 hours, and 36 (2.0\%) were transported between 24 and 48 hours after the initial response. Of these subsequent transports, $28.6 \%$ were for 'breathing problems' and $36.5 \%$ were for 'sick person' responses (figure 2).

Overall, one or more treatments were administered in $27.6 \%$ of CP responses $(n=657)$. Normal saline was the most common medication given $(n=372)$, and was most commonly administered for 'sick person' $(\mathrm{n}=186)$, 'breathing problems' $(\mathrm{n}=74)$ and 'unconscious/fainting' $(n=61)$. Responses for 'breathing problems' $(n=465)$ were most likely to have had medications administered including the following: oxygen $(\mathrm{n}=282)$; albuterol $(\mathrm{n}=202)$; furosemide $(\mathrm{n}=79)$; methylprednisolone $(\mathrm{n}=59)$; morphine $(\mathrm{n}=54)$. Aspirin was given most commonly for "chest pain' responses and dextrose for 'diabetic emergency' responses.

Patient/caregiver survey results are summarised in figure 3. A total of 1085 surveys were sent by mail to patients' homes who had received a CP response and 663 responses were received (response rate of 61.1\%). Overall, respondents reported high levels of satisfaction with the programme. Moreover, $87.0 \%$ strongly agreed and $11.0 \%$ agreed that goals of care were accounted for in the CP treatment plan, and 89\% strongly agreed and $11.0 \%$ agreed that they would use community paramedics in a future medical emergency. 


\begin{tabular}{|c|c|c|c|c|c|c|c|c|c|}
\hline \multirow[b]{2}{*}{ Chief Complaints } & \multicolumn{7}{|c|}{ Community Paramedicine Response AMPDS Codes } & \multirow{2}{*}{ 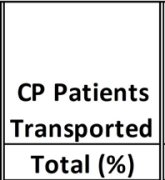 } & \multirow[t]{2}{*}{\begin{tabular}{|c|} 
CP Patients \\
transported \\
within 48 \\
hours
\end{tabular}} \\
\hline & ALPHA & BRAVO & CHARLIE & DELTA & ECHO & OMEGA & Total (\%) & & \\
\hline 01 - Abdominal Pain & 31 & 0 & 17 & 6 & 0 & 0 & $54(2.3)$ & $17(4.0)$ & $3(5.6)$ \\
\hline 02 - Allergies/Envenomations & 1 & 0 & 0 & 5 & 0 & 0 & $6(0.3)$ & $1(0.2)$ & $0(0.0)$ \\
\hline 05 - Back Pain (No-Trauma) & 3 & 0 & 0 & 1 & 0 & 0 & $4(0.2)$ & $1(0.2)$ & $0(0.0)$ \\
\hline 06 - Breathing Problems & 0 & 0 & 201 & 465 & 5 & 0 & $671(28.2)$ & $131(30.8)$ & $36(5.4)$ \\
\hline 09 - Cardiac Or Resp Arrest & 0 & 8 & 0 & 14 & 15 & 82 & $119(5.0)$ & $0(0.0)$ & $1(0.8)$ \\
\hline 10 - Chest Pain & 0 & 0 & 98 & 48 & 0 & 0 & $146(6.1)$ & $31(7.3)$ & $6(4.1)$ \\
\hline 11 - Choking & 1 & 0 & 0 & 5 & 0 & 0 & $6(0.3)$ & $0(0.0)$ & $0(0.0)$ \\
\hline 12 - Convulsions/Seizures & 3 & 0 & 14 & 11 & 0 & 0 & $28(1.2)$ & $6(1.4)$ & $1(3.6)$ \\
\hline 13 - Diabetic Emergency & 9 & 0 & 8 & 3 & 0 & 0 & $20(0.8)$ & $7(1.6)$ & $0(0.0)$ \\
\hline 16 - Eye Problems / Injuries & 0 & 1 & 0 & 1 & 0 & 0 & $2(0.1)$ & $0(0.0)$ & $0(0.0)$ \\
\hline 17 - Falls & 185 & 111 & 0 & 16 & 0 & 0 & $312(13.1)$ & $38(8.9)$ & $14(4.5)$ \\
\hline 18 - Headache & 1 & 1 & 4 & 0 & 0 & 0 & $6(0.3)$ & $2(0.5)$ & $0(0.0)$ \\
\hline 19 - Heart Problems/AICD & 0 & 0 & 14 & 18 & 0 & 0 & $32(1.3)$ & $6(1.4)$ & $3(9.4)$ \\
\hline 21 - Haemorrhage/Lacerations & 10 & 11 & 0 & 26 & 0 & 0 & $47(2.0)$ & $19(4.5)$ & $4(8.5)$ \\
\hline 22 - Inaccessible Incident / Other Entrapment & 0 & 0 & 0 & 1 & 0 & 0 & $1(0.0)$ & $0(0.0)$ & $0(0.0)$ \\
\hline 23 - Overdose/Poisoning & 0 & 0 & 5 & 0 & 0 & 0 & $5(0.2)$ & $0(0.0)$ & $1(20.0)$ \\
\hline 25 - Psych/Suicide Attempt & 2 & 3 & 0 & 2 & 0 & 0 & $7(0.3)$ & $1(0.2)$ & $0(0.0)$ \\
\hline 26 - Sick Person & 271 & 34 & 169 & 147 & 0 & 9 & $630(26.5)$ & $104(24.4)$ & $46(7.3)$ \\
\hline 28 - Stroke/CVA & 1 & 0 & 59 & 0 & 0 & 0 & $60(2.5)$ & $19(4.5)$ & $2(3.3)$ \\
\hline 30 - Traumatic Injuries & 4 & 0 & 0 & 3 & 0 & 0 & $7(0.3)$ & $2(0.5)$ & $0(0.0)$ \\
\hline 31 - Unconscious/Fainting & 7 & 0 & 17 & 181 & 0 & 0 & $205(8.6)$ & $39(9.2)$ & $9(4.4)$ \\
\hline 32 - Unknown Problems & 0 & 10 & 0 & 0 & 0 & 0 & $10(0.4)$ & $2(0.5)$ & $0(0.0)$ \\
\hline Total CP Responses & 529 & 179 & 606 & 953 & 20 & 91 & $2378(100)$ & $426(100)$ & $126(100)$ \\
\hline \% Total Responses & $22.2 \%$ & $7.5 \%$ & $25.5 \%$ & $40.1 \%$ & $0.8 \%$ & $3.8 \%$ & $100.0 \%$ & & \\
\hline Death Pronouncements & 1 & 9 & 1 & 30 & 11 & 80 & 132 & & \\
\hline$\%$ Pronouncements & $0.2 \%$ & $5.0 \%$ & $0.2 \%$ & $3.1 \%$ & $55.0 \%$ & $87.9 \%$ & $5.6 \%$ & & \\
\hline Transported & 61 & 37 & 120 & 207 & 0 & 1 & 426 & & \\
\hline$\%$ Transported & $11.5 \%$ & $20.7 \%$ & $19.8 \%$ & $21.7 \%$ & $0.0 \%$ & $1.1 \%$ & $17.9 \%$ & & \\
\hline Transported Within 48 hours & 27 & 10 & 29 & 60 & 0 & 0 & 126 & & \\
\hline \% Transported Within 48 hours & $5.8 \%$ & $7.5 \%$ & $6.0 \%$ & $8.4 \%$ & $0.0 \%$ & $0.0 \%$ & $6.9 \%$ & & \\
\hline
\end{tabular}

Figure 2 Breakdown of community paramedicine responses and outcomes by AMPDS codes.

When asked what the individual would have done if community paramedics had not been available, 65.0\% stated they would have called 911, 24.8\% stated they would have gone to the ED, $10.0 \%$ stated they would have waited at home to see if the condition improved

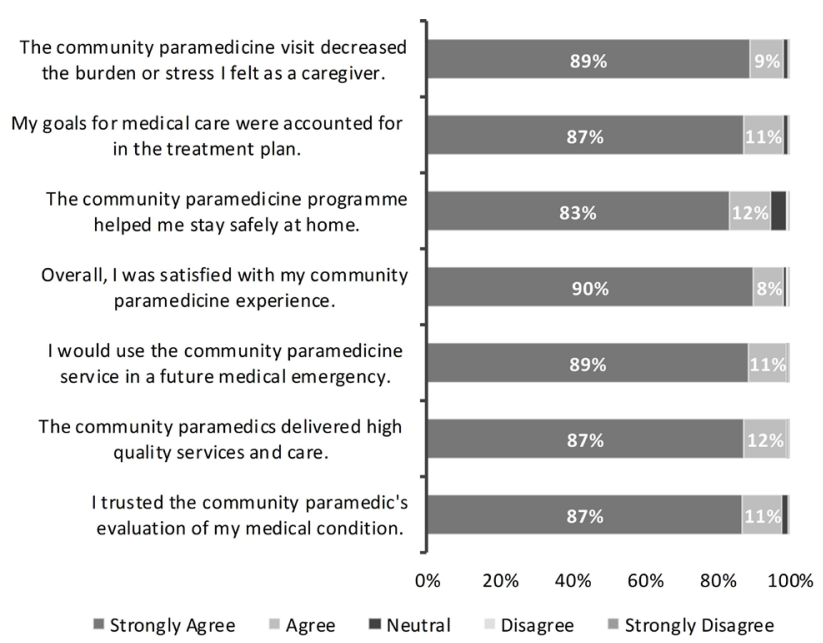

Figure 3 Patient/caregiver satisfaction survey results, $\mathrm{n}=633$. and $0.2 \%$ stated they would have done something else, with answers including calling the local fire department or calling their physician.

\section{DISCUSSION}

Our study demonstrates that, within the context of an AIM programme, a CP programme can provide a safe and effective option for responding to and treating frail older adults in their home, avoiding transport to the ED and likely hospitalisation. Moreover, the results of $\mathrm{CP}$ care in the home for an acute change in condition are associated with high levels of patient and family satisfaction and low levels of subsequent ED transport.

Our study is the first to link EMS triage codes (AMPDS) with CP transport rates within an AIM programme. These EMS triage codes are used in over $70 \%$ of major cities in the USA for the purpose of dispatching appropriate emergency response resources based on call acuity. In our study, the overall ED transport rates in our programme were $17.9 \%$, and even among the high acuity responses (CHARLIE and DELTA), only $21.0 \%$ required transport to the ED at the time of the CP response. Transport of high acuity 
responses to the ED at 24 and 48 hours post-CP visit was also infrequent. Importantly, in post-CP visit surveys, in nearly $90 \%$ of cases patients and caregivers reported that they would have either called 911 or gone directly to the emergency room had CP not been available.

It is important to note that, in the absence of a CP programme, the majority of chronically ill older adults with acute changes in condition are addressed by the 911 EMS system. Older adults account for a large proportion of EMS responses, use EMS at a disproportionately higher rate than younger adults and are at a high risk of using EMS for repeat transports within 30 days, with breathing problems and falls being statistically significant contributors to repeat EMS transports. ${ }^{13}{ }^{14}$ In contrast to our programme's results, published literature has shown that ED transport rates in a traditional EMS system are generally 91\%-98\%. ${ }^{15-17}$ One study using the AMPDS triage system showed a substantially higher rate of non-transport $(25 \%)$, though codes with high non-transport rates were not seen in our study (ie, traffic accidents, sexual assault). ${ }^{18}$ The reason for these high rates of transport is in part due to the fact that the 911 EMS system is regulated by the Department of Transportation and personnel working in this system have no option other than to transport patients to the ED. In fact, there is no reimbursement for an EMS response that does not result in ED transport, even if the patient and family refuse. ${ }^{5}$

Once in the ED, due to medical complexity, frailty and uncertain availability of ambulatory follow-up, older adults experiencing a change in condition are highly likely to be admitted. ${ }^{19-23}$ Moreover, both medical and legal concerns on the part of ED providers and current CMS financial incentives favour hospital admission even for patients at the end of life despite the considerable literature supporting the potential for iatrogenic injury and high cost of hospital utilisation and post-acute care at the end of life. ${ }^{24}{ }^{25}$ Indeed, in addition to associated decline in cognitive and functional status, hospitalisation of frail chronically ill individuals significantly increases the probability of post-hospital nursing home care placement. ${ }^{26-28}$

Our results add to the body of literature supporting the ability of paramedics with medical backup to provide urgent and emergent care in the home for those who are homebound, frail and advanced age. CP programmes are growing in popularity among homebased primary care programmes and literature is beginning to emerge to support benefits of non-traditional roles for EMS among older frail populations. Recent published data include small studies of CP being used to support complex and older patients in the home, and demonstrate patient acceptance of the model. ${ }^{29-31}$ One randomised controlled trial of a paramedic-led, community-based health promotion programme for vulnerable adults in a public housing community in
Canada showed decreased 911 calls and ambulance transports, as well as improved quality of life for those in the intervention group. ${ }^{32} 33$ Lastly, a recent review of eight CP studies in the USA showed promise for decreased ED and hospital utilisation, but commented on lack of quantification of impact on cost of care across studies. $^{34}$

Propagation of the CP model is currently limited by several factors. First, as noted above, in-home care provided by paramedics and other EMS responders that does not culminate in hospital transport is not traditionally reimbursed, which has implications for policy-makers. Second, local and state regulations on EMS services vary by state and county and may limit programme growth. Additionally, regulatory heterogeneity makes standardisation of best practices in this space difficult. ${ }^{35}$ Third, AIM programmes may not have relationships with EMS agencies, making incentives for partnerships misaligned in current fee-for-service reimbursement models.

Strengths of this study include the comprehensive nature of the data set, with detailed EMS data (AMPDS codes, response times, medications given) combined with physician practice data (visit outcomes and postvisit transport rates), and patient satisfaction surveys (CP visit satisfaction as well as reports on what would have been done without the programme), as well as having a sizeable sample size over the 4-year study period. Study limitations include observational design with no control group. The patient population, while representative of those with advanced illness, limits the generalisability of the findings to broader geriatrics populations. Additionally, rates of advance care planning in the study population were high, may not be generalisable to non-AIM populations, and generally aligned around in-home evaluation and treatment.

In addition to elucidating optimal role in the community, future research in the field of CP will need to quantify cost-savings in the model of care. Medicare's Independence at Home demonstration has shown total cost of care savings of $17 \%$ for the nine of 17 homebased primary care programmes that surpassed the 5\% mandatory savings threshold, mainly by reducing ED and hospital utilisation. Some of these programmes included $\mathrm{CP}$, though the cost savings directly attributable to $\mathrm{CP}$ have not been quantified. ${ }^{36}$ Attributing cost savings to specific programmatic components and determining programmatic best practices will be important, as home-based primary care programmes even without $\mathrm{CP}$ can provide a reduction in $\mathrm{ED}$ visit and hospitalisation rates. ${ }^{3738}$

In conclusion, our study demonstrates that community paramedics, operating within a multidisciplinary AIM programme and with direct access to medical control, can treat high acuity conditions that would otherwise result in transport to the ED in a conventional 911 system. Our results support this model as an effective and safe method for allowing older adults to 
age in place. Further studies should examine the financial implications and cost-effectiveness of this model, with the goal of informing alignment of incentives and reimbursement with high-quality care when and where patients need and want it: on-demand, 24/7, in the home. We predict that $\mathrm{CP}$ will likely prove an invaluable tool in driving patient and family satisfaction, while reducing total cost of care across populations.

Acknowledgements The authors would like to acknowledge Karin Rhodes, MD, MS for her input into the discussion and edits to the final draft.

Contributors JW and KLS conceived of the programme. $\mathrm{KAA}, \mathrm{AR}, \mathrm{AP}$ and JZ designed the study. KAA and MG supervised the conduct of the research. AP and JZ performed the data analysis. KAA drafted the manuscript and all authors contributed substantially to its revision. KAA takes responsibility for the paper as a whole.

Funding This programme and research study was supported by Northwell Health.

\section{Competing interests JW provides consulting services for EMS} agencies.

\section{Patient consent for publication Not required.}

Ethics approval This study was approved by the Northwell Health Institutional Review Board (IRB), study 15-243. Documentation of informed consent was not required due to the nature of the study (retrospective chart review) as per IRB protocols.

Provenance and peer review Not commissioned; externally peer reviewed.

Open access This is an open access article distributed in accordance with the Creative Commons Attribution Non Commercial (CC BY-NC 4.0) license, which permits others to distribute, remix, adapt, build upon this work noncommercially, and license their derivative works on different terms, provided the original work is properly cited, appropriate credit is given, any changes made indicated, and the use is noncommercial. See: http://creativecommons.org/licenses/by-nc/4. $0 /$.

\section{REFERENCES}

1 Ackroyd-Stolarz S, Read Guernsey J, Mackinnon NJ, et al. The association between a prolonged stay in the emergency department and adverse events in older patients admitted to hospital: a retrospective cohort study. BMJ Qual Saf 2011;20:564-9.

2 Thomas EJ, Studdert DM, Burstin HR, et al. Incidence and types of adverse events and negligent care in Utah and Colorado. Med Care 2000;38:261-71.

3 Forster AJ, Clark HD, Menard A, et al. Adverse events among medical patients after discharge from hospital. CMAJ 2004;170:345-9.

4 French EB, McCauley J, Aragon M, et al. End-of-life medical spending in last twelve months of life is lower than previously reported. Health Aff 2017;36:1211-7.

5 Iezzoni LI, Dorner SC, Ajayi T. Community paramedicineaddressing questions as programs expand. $\mathrm{N}$ Engl J Med 2016;374:1107-9.

6 Abrashkin KA, Washko J, Zhang J, et al. Providing acute care at home: community paramedics enhance an advanced illness management program-preliminary data. J Am Geriatr Soc 2016;64:2572-6.

7 Choi BY, Blumberg C, Williams K. Mobile integrated health care and community paramedicine: an emerging emergency medical services concept. Ann Emerg Med 2016;67:361-6.
8 Mi R, Hollander MM, Jones CMC, et al. A randomized controlled trial testing the effectiveness of a paramedicdelivered care transitions intervention to reduce emergency department revisits. BMC Geriatr 2018;18.

9 Huff C. Paramedicine programs making house calls but scope of practice under scrutiny. Ann Emerg Med 2017;69:A13-A16.

10 Williams JG, Bachman MW, Lyons MD, et al. Improving decisions about transport to the emergency department for assisted living residents who fall. Ann Intern Med 2018;168:179-86.

11 CMS.gov. Emergency Triage, Treat, and Transport (ET3) Model. Available: https:/innovation.cms.gov/initiatives/et3/ [Accessed 20 Feb 2019].

12 Katz S, Ford AB, Moskowitz RW, et al. Studies of illness in the aged. the index of ADL: a standardized measure of biological and psychosocial function. JAMA 1963;185:914-9.

13 Shah MN, Bazarian JJ, Lerner EB, et al. The epidemiology of emergency medical services use by older adults: an analysis of the National Hospital Ambulatory medical Care Survey. Academic Emergency Medicine 2017;14:441-7.

14 Evans CS, Platts-Mills TF, Fernandez AR, et al. Repeated emergency medical services use by older adults: analysis of a comprehensive statewide database. Ann Emerg Med 2017;70:506-15.

15 Moss ST, Chan TC, Buchanan J, et al. Outcome study of prehospital patients signed out against medical advice by field paramedics. Ann Emerg Med 1998;31:247-50.

16 Holder P, Arthur AO, Thiems G, et al. Patients refusing prehospital transport are increasingly likely to be geriatric. Emerg Med Int 2012;2012:1-3.

17 Stark G, Hedges JR, Neely K, et al. Patients who initially refuse prehospital evaluation and/or therapy. Am J Emerg Med 1990;8:509-11.

18 Hodell EM, Sporer KA, Brown JF. Which emergency medical dispatch codes predict high prehospital nontransport rates in an urban community? Prehosp Emerg Care 2014;18:28-34.

19 Shaleah L, Karishma C, DeFrances C. Hospitalizations for patients aged 85 and over in the United States, 2000-2010. NCHS Data Brief 2015:1-8.

20 Lo AX, Flood KL, Biese K, et al. Factors associated with hospital admission for older adults receiving care in U.S. emergency departments. J Gerontol A Biol Sci Med Sci 2017;72:1105-9.

21 Ornstein KA, Leff B, Covinsky KE, et al. Epidemiology of the homebound population in the United States. JAMA Intern Med 2015;175:1180-6.

22 Legramante JM, Morciano L, Lucaroni F, et al. Frequent use of emergency departments by the elderly population when continuing care is not well established. PLoS One 2016;11:e0165939.

23 Wolff JL, Starfield B, Anderson G. Prevalence, expenditures, and complications of multiple chronic conditions in the elderly. Arch Intern Med 2002;162:2269-76.

24 Improving Quality and Honoring Individual Preferences Near the End of Life. Committee on Approaching Death. Addressing key end of life issues; Institute of Medicine. Washington (DC: National Academies Press (US), 2015.

25 Boltz M, Capezuti E, Shabbat N, et al. Going home better not worse: older adults' views on physical function during hospitalization. Int J Nurs Pract 2010;16:381-8.

26 Dwyer R, Gabbe B, Stoelwinder JU, et al. A systematic review of outcomes following emergency transfer to hospital for residents of aged care facilities. Age Ageing 2014;43:759-66.

27 Smith ER, Stevens AB. Predictors of discharges to a nursing home in a hospital-based cohort. J Am Med Dir Assoc 2009;10:623-9.

28 Kelley AS, Ettner SL, Morrison RS, et al. Determinants of medical expenditures in the last 6 months of life. Ann Intern Med 2011;154:235-42. 
29 Chellappa DK, DeCherrie LV, Escobar C, et al. Supporting the on-call primary care physician with community paramedicine. Intern Med J 2018;48:1261-4.

30 Kant RE, Vejar M, Parnes B, et al. Outcomes and provider perspectives on geriatric care by a nurse practitionerled community paramedicine program. Geriatr Nurs 2018;39:574-9.

31 Dainty KN, Seaton MB, Drennan IR, et al. Home visit-based community paramedicine and its potential role in improving patient-centered primary care: a grounded theory study and framework. Health Serv Res 2018;53:3455-70.

32 Agarwal G, Angeles R, Pirrie M, et al. Evaluation of a community paramedicine health promotion and lifestyle risk assessment program for older adults who live in social housing: a cluster randomized trial. Can Med Assoc J 2018;190:E638 -E647.

33 Agarwal G, Angeles R, Pirrie M, et al. Reducing 9-1-1 emergency medical service calls by implementing a community paramedicine program for vulnerable older adults in public housing in Canada: a multi-site cluster randomized controlled trial. Prehosp Emerg Care
34 Gregg A, Tutek J, Leatherwood MD, et al. Systematic review of community paramedicine and EMS mobile integrated health care interventions in the United States. Popul Health Manag 2019. doi:10.1089/pop.2018.0114. [Epub ahead of print: 07 Jan 2019].

35 Bigham BL, Kennedy SM, Drennan I, et al. Expanding paramedic scope of practice in the community: a systematic review of the literature. Prehosp Emerg Care 2013;17:361-72.

36 Kinosian B, Taler G, Boling P, et al. Projected savings and workforce transformation from converting independence at home to a Medicare benefit. J Am Geriatr Soc 2016;64:1531-6.

37 Schamess A, Foraker R, Kretovics M, et al. Reduced emergency room and hospital utilization in persons with multiple chronic conditions and disability receiving home-based primary care. Disabil Health J 2017;10:326-33.

38 Stall N, Nowaczynski M, Sinha SK. Systematic review of outcomes from home-based primary care programs for homebound older adults. J Am Geriatr Soc 2014;62:2243-51. 